Check for updates

Cite this: RSC Adv., 2019, 9, 21793

\title{
The behaviour of water on the surface of kaolinite with an oscillating electric field
}

\author{
Bo Liao, (D) Li Qiu, Diansheng Wang, Wancheng Bao, Yupeng Wei \\ and Yudou Wang (D) *
}

A quantitative understanding of oscillating electric field effects on the behaviour of water on the surface of kaolinite is vital for research in the field of clay-water systems. The behaviour of water molecules on the $(0$ 01 ) and $\left(\begin{array}{ll}0 & 0\end{array}-1\right)$ surfaces of kaolinite are systematically investigated in the absence or presence of an oscillating electric field using molecular dynamics simulations. The simulated results demonstrate that the applied oscillating electric fields parallel to kaolinite surface contribute to decreased amounts of adsorbed water molecules on the $\left(\begin{array}{llll}0 & 0 & 1\end{array}\right)$ surface of kaolinite. The oscillating electric field performs an inconspicuous effect on the adsorption of water on the $\left(\begin{array}{ll}0 & 0\end{array}-1\right)$ surface of kaolinite. The behaviour of water on the surface of kaolinite will be impacted more severely by oscillating electric fields. Our results demonstrate that water molecules will rotate following the directions of the applied fields, which causes the decrease of hydrogen bonds, and thus, the weaker water-kaolinite interactions due to the applied field drive water molecules away from kaolinite surfaces. These results are of significance to understand the mechanisms of the oscillating electric fields affecting the behaviour of clay-water systems.

Received 6th June 2019

Accepted 9th July 2019

DOI: 10.1039/c9ra04269e

rsc.li/rsc-advances
In recent years, a variety of external electrical fields were applied into nuclear waste treatments, micro/nano devices manufacturing, degradation of environmentally harmful organic compounds, and petroleum industry. ${ }^{7-13}$ The structure and properties of water-solids interfaces under the influence of an external electric field are quite important for these fields. Except the thermal effects of oscillating electric fields, ${ }^{14}$ the nonthermal effects of electric field on matter are another key factor changing the properties of water-solid interfaces. Some studies of the structures and properties of water-solids interfaces under applied electric fields have appeared. English and Futera have investigated the effects of external static electric fields applied to $\mathrm{TiO}_{2}$ /water interfaces by non-equilibrium molecular dynamics techniques. ${ }^{8,15,16}$ Song et al. ${ }^{17,18}$ and Zong et al. ${ }^{19}$ found that the wetting properties of water droplets on some solid faces are changed by an external electric field using molecular dynamics simulations. Some researchers have shown that external electric fields can control water flow direction in nanochannels and enhance ion separation or water purification in carbon nanotubes or other porous membranes. The relationships between flow velocity and strength or frequency of electric field have been discussed. ${ }^{\mathbf{2 0 , 2 1}}$ Moreover, the effect of electric fields on water viscosity has been explained by Zong et al. ${ }^{22}$ Although the behaviour of water on the surface of clays has been researched for many years, ${ }^{\mathbf{4} 23-30}$ the effects of oscillating electrical fields on water behaviour on the surface of clays are not completely understood.

In this paper, the molecular dynamics simulations (MD) were performed to investigate the behaviour of water on the 
surfaces of kaolinite with oscillating electric field. The behaviour of water on octahedral and tetrahedral surfaces of the kaolinite was studied and compared, and their different behaviour were attributed to the different chemical natures of the two surfaces. The effects of direction, intensity, and frequency of external oscillating electric field on the behaviour of water on these two surfaces of kaolinite were studied. We mainly analyzed the density distribution and radial distribution functions of the water in the pores under the effects of oscillating electric field. In order to thoroughly understand the effects of electrical field on the behaviour of water on the surfaces of kaolinite, the dipole moments of water molecules, hydrogen bonds, interaction energy between kaolinite and water were carefully examined.

\section{Methodology}

The system simulated only consists of kaolinite and water. The initial structure of the water molecules and the pore wall with different surface of kaolinite in the simulation system were shown in Fig. 1. Water molecules were described using the simple point charge SPC/E model. ${ }^{31}$ The angle and the length of water molecular were $109^{\circ} 47^{\prime}$ and $0.100 \mathrm{~nm}$ which as shown in Fig. 1a. The model of hydrated kaolinite contained 898 water molecules to make the bulk density of water equal to $1 \mathrm{~g} \mathrm{~cm}^{-3}$. Kaolinite, of which the unite cell used in this work can be presented as $\mathrm{Si}_{4} \mathrm{Al}_{4} \mathrm{O}_{10}(\mathrm{OH})_{8}$, was a $1: 1$ clay mineral. ${ }^{32}$ As a result, kaolinite naturally formed two types of internal surface pores, one was $\left(\begin{array}{lll}0 & 0 & 1\end{array}\right)$ surface which was covered by hydroxyl and another one was $\left(\begin{array}{lll}0 & 0 & -1\end{array}\right)$ surface which was covered by silicon and oxygen. The $\left(\begin{array}{lll}0 & 0 & 1\end{array}\right)$ surface and $\left(\begin{array}{lll}0 & 0 & -1\end{array}\right)$ surface of kaolinite were chosen as the solid substrate to study the behaviour of water on the surfaces of kaolinite with oscillating electric fields, ${ }^{33}$ as shown in Fig. $1 \mathrm{~b}$ and c, respectively. Molecular dynamic simulations were performed to study the adsorption/ desorption of water in a pore space of kaolinite platelets (approximately $3 \mathrm{~nm}$ wide). The simulation model sizes along the $x, y$ and $z$ directions were $25.75 \AA$, $35.72 \AA$ and $58.08 \AA$,

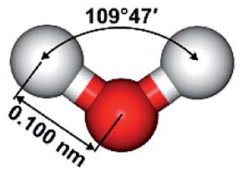

(a)

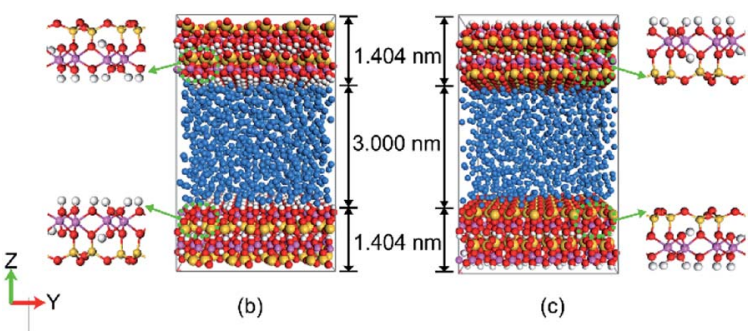

Fig. 1 Snapshot of (a) water molecules, (b) simulation model of $\left(\begin{array}{lll}0 & 0 & 1\end{array}\right)$ and $(c)$ simulation model of $(00-1)$ with the color scheme: water, blue; Si, yellow; $\mathrm{Al}$, pink; $\mathrm{O}$ and $\mathrm{H}$, red and white. respectively. In our simulations, all atoms of kaolinite remain fixed and the CLAYFF force field ${ }^{34}$ was employed to describe kaolinite.

The non-bond interactions among all atoms in the simulation system were described by: ${ }^{35}$

$$
\begin{gathered}
U\left(r_{\mathrm{ab}}\right)=U^{\mathrm{LJ}}+U^{\mathrm{C}} \\
=4 \varepsilon_{\mathrm{ab}}\left[\left(\frac{\sigma_{\mathrm{ab}}}{r_{\mathrm{ab}}}\right)^{12}-\left(\frac{\sigma_{\mathrm{ab}}}{r_{\mathrm{ab}}}\right)^{6}\right]+\frac{q_{\mathrm{a}} q_{\mathrm{b}}}{4 \pi \varepsilon_{0} r_{\mathrm{ab}}}+q_{\mathrm{a}} r_{\mathrm{a}} E
\end{gathered}
$$

Where $E$ is the external electric field, and $r_{\mathrm{a}}$ is the dislocation of the charged atom a. The parameter $q_{\mathrm{a}}$ and $q_{\mathrm{b}}$ are the partial charges of the atoms a and $\mathrm{b}$, and $r_{\mathrm{ab}}$ is the distance between the centers of $\mathrm{a}$ and $\mathrm{b}$ atoms. The parameter $\varepsilon_{0}$ is the dielectric permittivity of vacuum, and $\varepsilon_{\mathrm{ab}}$ controls the strength of the short-range interactions. The LJ diameter $\sigma_{\mathrm{ab}}$ is used to set the length scale. The LJ parameters $\sigma_{\mathrm{ab}}$ and $\varepsilon_{\mathrm{ab}}$ are deduced from the conventional Lorentz-Berthelot combining rules:

$$
\begin{gathered}
\sigma_{\mathrm{ab}}=\frac{\sigma_{\mathrm{a}}+\sigma_{\mathrm{b}}}{2} \\
\varepsilon_{\mathrm{ab}}=\sqrt{\varepsilon_{\mathrm{a}} \varepsilon_{\mathrm{b}}}
\end{gathered}
$$

Long-range electrostatic interaction was calculated by the particle-particle particle-mesh (PPPM) summation algorithm with a convergence parameter of $10^{-8}$, and the cutoff of nonbonded interaction was set to be $10.0 \AA$ A. Table 1 contained all the parameters that used in this work.

The applied oscillating electric fields were expressed as follows: ${ }^{16,36}$

$$
E(t)=\sqrt{2} E \sin (\omega t)
$$

where $E$ is the effective value and $T$ is vibration periods of the strength of oscillating electric fields. Herein, the $E$ values of $0.05 \mathrm{~V}^{-1}, 0.10 \mathrm{~V}^{-1}, 0.15 \mathrm{~V}^{-1}, 0.20 \mathrm{~V}^{-1}$, and $0.25 \mathrm{~V}^{-1}$ and oscillating vibration periods $T=100 \mathrm{ps}, 40 \mathrm{ps}, 30 \mathrm{ps}, 20 \mathrm{ps}$, and $10 \mathrm{ps}$, which is corresponding to frequency $f$ of $10.0 \mathrm{GHz}, 25.0$ $\mathrm{GHz}, 33.3 \mathrm{GHz}, 50.0 \mathrm{GHz}$, and $100 \mathrm{GHz}$, respectively, were comparative study.

All calculations were done by the LAMMPS (Large-scale Atomic/Molecular Massively Parallel Simulator) software package under the NVT ensemble. ${ }^{37}$ The time step of MD

Table 1 Lennard-Jones parameters and atomic charge ${ }^{a}$

\begin{tabular}{llll}
\hline Atom & $\varepsilon\left(\mathrm{kcal} \mathrm{mol}^{-1}\right)$ & $\sigma(\AA)$ & $q(\mathrm{e})$ \\
\hline Water & & & \\
$\mathrm{O}$ & 0.1553 & 3.1660 & -0.8476 \\
$\mathrm{H}$ & 0 & 0 & 0.4238 \\
& & & \\
Kaolinite & & & \\
$\mathrm{Al}$ & $1.3297 \times 10^{-6}$ & 4.2713 & 1.575 \\
$\mathrm{Si}$ & $1.8402 \times 10^{-6}$ & 3.3020 & 2.100 \\
$\mathrm{O}^{\mathrm{b}}$ & 0.1554 & 3.1655 & -1.050 \\
$\mathrm{O}^{\mathrm{h}}$ & 0.1554 & 3.1655 & -0.950 \\
$\mathrm{H}$ & 0 & 0 & 0.425
\end{tabular}

${ }^{a} \mathrm{O}^{\mathrm{b}}$ : bridging oxygen; $\mathrm{O}^{\mathrm{h}}$ : hydroxyl oxygen. 
simulation was $1.0 \mathrm{fs}$ and the temperature was controlled by the Nose-Hoover thermostat ${ }^{38}$ at $333.15 \mathrm{~K}$. Only the last $2.0 \mathrm{~ns}$ of equilibrium molecular dynamics (EMD) trajectories in $4.0 \mathrm{~ns}$ were collected for data acquisition and analysis for all the cases without electric fields applying. Then, 5.0 ns non-equilibrium molecular dynamics (NEMD) trajectories were used to stabilize the system based on 4.0 ns EMD trajectories, and then the final $4.0 \mathrm{~ns}$ was used for sampling and analysis of the nonequilibrium data.

\section{Results and discussion}

\subsection{Effects of directions of oscillating electric fields on water behaviour}

To discuss the behaviour of water in kaolinite with oscillating electric fields, the directions of oscillating electric fields should be studied preferentially. ${ }^{22,39}$ Considering the configuration of system and anisotropy of hydroxyl on the surface of kaolinite, we applied an electric field with $0.25 \mathrm{~V}^{-1}$ and $100 \mathrm{GHz}$ along $x$, $y$ and $z$ directions of $\left(\begin{array}{lll}0 & 0 & 1\end{array}\right)$ and $\left(\begin{array}{lll}0 & 0 & -1\end{array}\right)$ sheet, respectively. Fig. 2 shows the effects of directions of electric fields on the density distribution of water molecules. Three adsorption layers are formed on $\left(\begin{array}{lll}0 & 0 & 1\end{array}\right)$ and $\left(\begin{array}{lll}0 & 0 & -1\end{array}\right)$ surfaces, but the third adsorption layer of $\left(\begin{array}{lll}0 & 0 & 1\end{array}\right)$ surface is not obvious. It is clear that the first
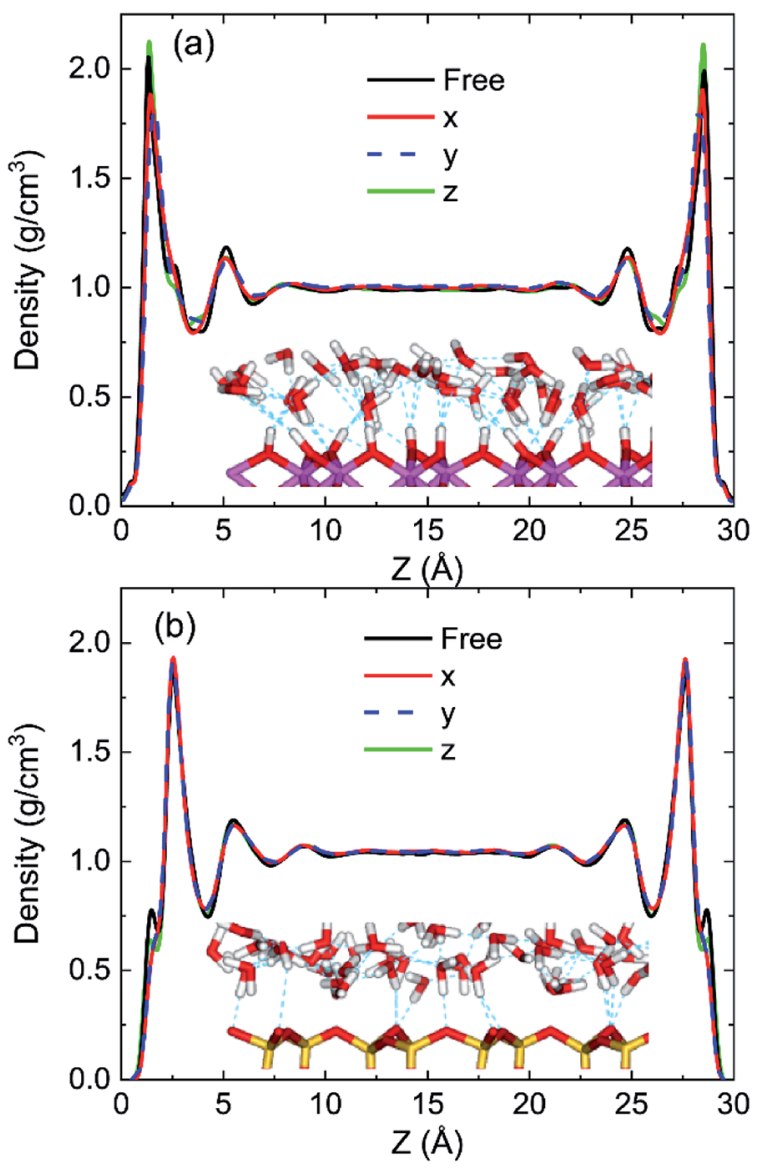

Fig. 2 Density distribution of water in the pore along the $z$ direction of simulation model with different directions of oscillating electric fields $\left(333.15 \mathrm{~K}, 100 \mathrm{GHz}, 0.25 \mathrm{~V} \AA^{-1}\right)$ : (a) (0 0 1) surface, (b) (0 0 -1) surface. water adsorption layer on the $\left(\begin{array}{lll}0 & 0 & 1\end{array}\right)$ surface is formed at $z=$ $1.249 \AA$ from the pore walls, which is closer than the first water adsorption layer on the $\left(\begin{array}{lll}0 & 0 & -1\end{array}\right)$ surface at $z=2.768 \AA$. Furthermore, the first adsorption layer on the (llll) surface has denser water molecules compared with the $\left(\begin{array}{lll}0 & 0 & -1\end{array}\right)$ surface. This phenomenon can be attributed to the fact that the $\left(\begin{array}{lll}0 & 0 & 1\end{array}\right)$ surface of kaolinite is covered with hydroxyl while the $\left(\begin{array}{lll}0 & 0 & -1\end{array}\right)$ surface of kaolinite is covered with silicon-oxygen, thus, the kaolinite $\left(\begin{array}{lll}0 & 0 & 1\end{array}\right)$ surface (hydroxyl surface) is more hydrophilic than $(00-1)$ surface (silicon-oxygen surface) because hydrogen bonds are easily formed between hydroxyl and water molecules. ${ }^{40}$ Fig. $2 \mathrm{a}$ and $\mathrm{b}$ also show the configuration snapshots of the two kinds of surfaces forming hydrogen bonds with water without electric fields. The statistical results show that 142 hydrogen bonds are formed on $\left(\begin{array}{lll}0 & 0 & 1\end{array}\right)$ surface and 29 hydrogen bonds are formed on $(00-1)$ surface, as shown in Fig. 3.

The first adsorption layer of $\left(\begin{array}{lll}0 & 0 & 1\end{array}\right)$ surface changes greatly when the electric field was applied. Fig. 2a shows that the peak of the first adsorption layer on the $\left(\begin{array}{lll}0 & 0 & 1\end{array}\right)$ surface decreases from $2.055 \mathrm{~g} \mathrm{~cm}^{-3}$ to $1.885 \mathrm{~g} \mathrm{~cm}^{-3}$ or $1.814 \mathrm{~g} \mathrm{~cm}^{-3}$ when electric field was applied in the $x$ or $y$ direction. And there is a slight increase in the peak of the first adsorption layer when electric field was applied in the $z$ direction. Due to the polarity of water molecule, it would rotate following the oscillating electric fields according to the direction and frequency of applied oscillating electric fields, and therefore, the applied oscillating electric field leads to a decrease of the number of hydrogen bonds between hydroxyl and water molecules, leading to desorb of water molecules from the surface. From Fig. 3, we know that the number of hydrogen bonds decreases from 142 to 116 or 108 when electric field was applied in $x$ or $y$ direction. But just few hydrogen bonds are broken when electric field was applied along $z$ direction. The effects of electric fields on density distribution of water on $\left(\begin{array}{lll}0 & 0 & -1\end{array}\right)$ surface are, however, limited whatever direction the electric field is, as Fig. $2 \mathrm{~b}$ shows. Although only 29 hydrogen bonds are formed between water molecules and the $(00-1)$ surface of kaolinite which is covered by silicon-oxygen without electric fields, as Fig. 3 shows, most of the hydrogen bonds remain when electric field was applied.

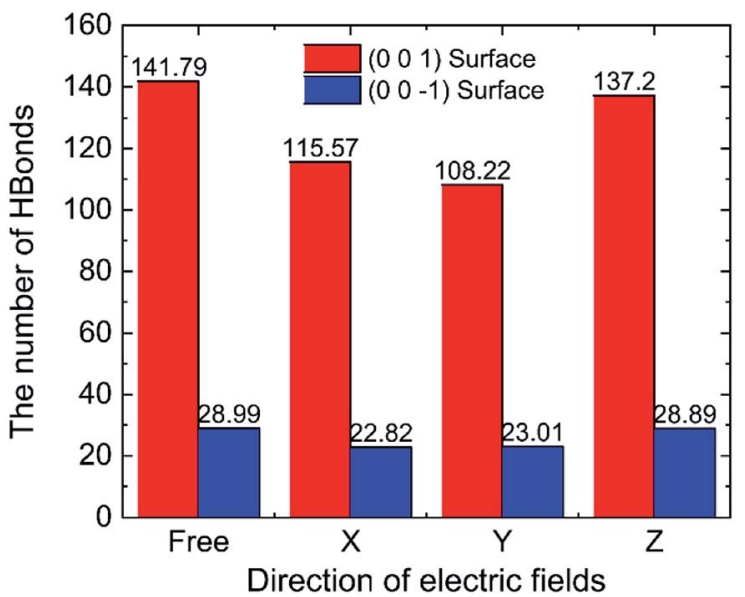

Fig. 3 The number of hydrogen bonds with different directions of oscillating electric fields. 
The radial distribution functions (RDFs) between oxygen of hydroxyl on kaolinite $\left(\begin{array}{lll}0 & 0 & 1\end{array}\right)$ surface and oxygen of water $\left(\mathrm{O}_{\mathrm{Sur}(1}\right)^{-}$ $\left.\mathrm{O}_{\mathrm{W}}\right)$ and the RDFs between oxygen of hydroxyl on $\left(\begin{array}{lll}0 & 0 & -1\end{array}\right)$ surface and oxygen of water $\left(\mathrm{O}_{\mathrm{Sur}(-1)}-\mathrm{O}_{\mathrm{W}}\right)$ are shown in Fig. 4. Owing to the value of cutoff $(10.0 \AA)$ of the non-bonded interaction and the dimension of the pore (half of the dimension of pore of kaolinite is $15.0 \AA$ ), the RDFs were presented in the range of $12.5 \AA$. The peak of two RDFs describe the distribution of oxygen atoms of water around the oxygen atoms of hydroxyl. From the first peak of Fig. 4a, it is obvious that the distribution of water molecule changes after applying an electric field in $x, y$ and $z$ directions and the spatial distribution of water molecules can be greatly influenced by the applied electric field along $y$ direction on kaolinite (l $\left.\begin{array}{lll}0 & 0 & 1\end{array}\right)$ surface. However, the same phenomenon is not obvious in Fig. $4 \mathrm{~b}$, the electric fields in different directions have limited effect on the spatial distribution of water molecules on the $\left(\begin{array}{lll}0 & 0 & -1\end{array}\right)$ surface of kaolinite. We can infer that the presence of hydroxyl groups plays an important role in the spatial distribution and orientation of water molecules in kaolinite pores.

The spatial orientation of water molecules will be influenced by oscillating electric fields because of the permanent dipole moment of it. ${ }^{41}$ The average dipole moment of water along the
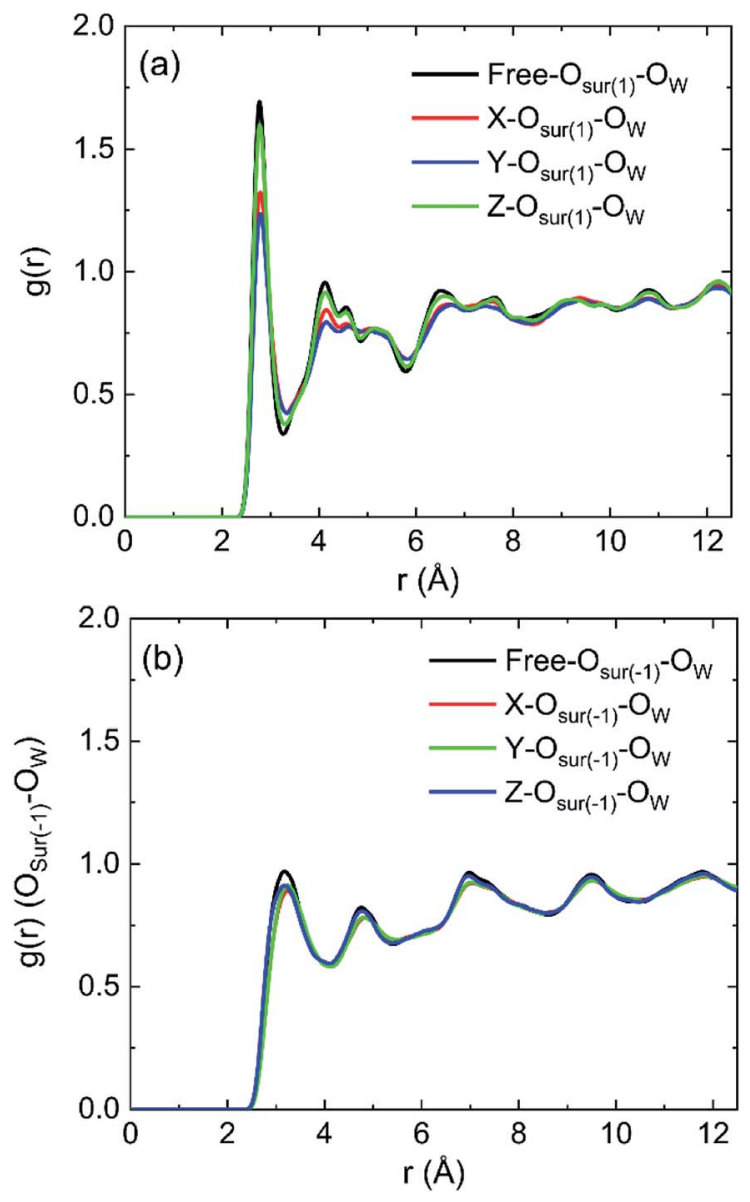

Fig. 4 The RDFs between water and atoms in kaolinite with different directions of electric fields: (a) oxygen of hydroxyl on the $\left(\begin{array}{lll}0 & 0 & 1\end{array}\right)$ surface of kaolinite and oxygen of water $\left(\mathrm{O}_{\mathrm{Sur}(1)}-\mathrm{O}_{\mathrm{W}}\right)$, (b) oxygen of hydroxyl on the $(00-1)$ surface of kaolinite and oxygen of water $\left(O_{\operatorname{sur}(-1)}-O_{W}\right)$.
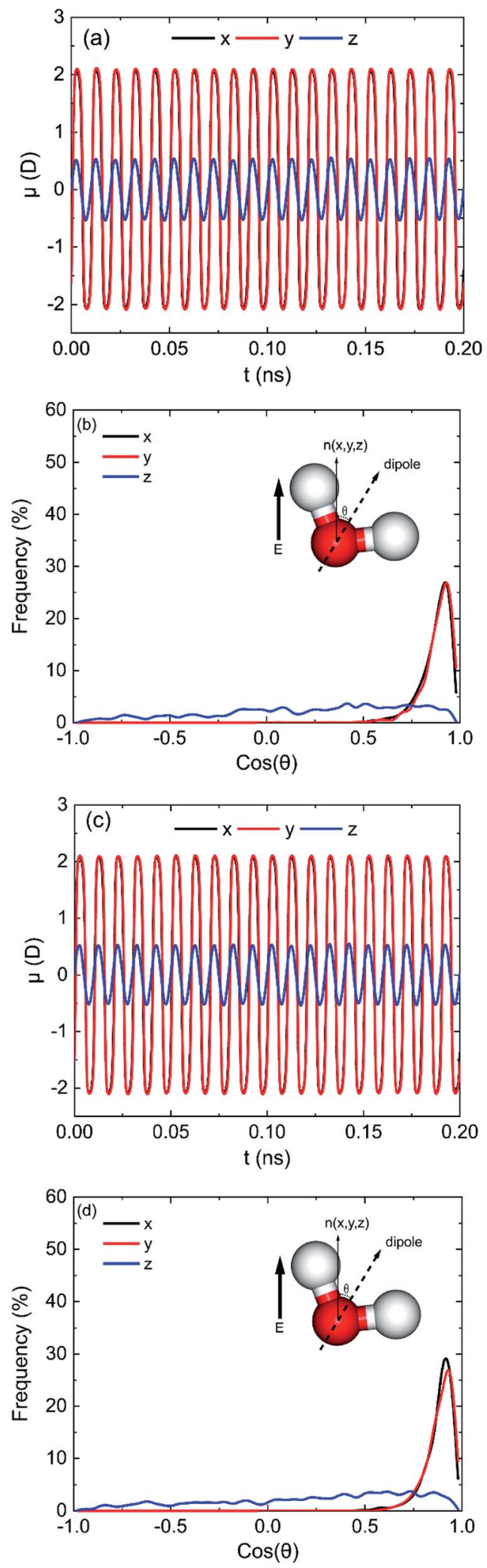

Fig. 5 Average dipole moment and statistical results of $\cos \theta$ for different directions of electric fields with $0.25 \vee \AA^{-1}$ and $100 \mathrm{GHz}$ : (a) (0 0 1) surface, (b) $\left(\begin{array}{lll}0 & 0 & 1\end{array}\right)$ surface, (c) $(00-1)$ surface and (d) $(00-1)$ surface. 
directions of electric fields, $\mu_{x}, \mu_{y}$ and $\mu_{z}$, are calculated to show the degree of molecular alignment with the electric field when oscillating electric fields were applied along the $x, y$, and $z$ directions of the simulation box, respectively:

$$
\mu_{n}=\frac{1}{N} \sum_{i=1}^{N} \mu_{n, i} \quad(n=x, y, z)
$$

where $N$ is the total number of water molecules. $\mu_{n, i}$ represents the $n$-component ( $x, y$ and $z$ component) of the dipole moment of each individual molecule. The values of $\mu_{x}, \mu_{y}$ and $\mu_{z}$ depend on the orientation of the water molecules in the pore of kaolinite.

Fig. 5a shows the results of average dipole moment $(\mu)$ of all 898 water molecules in oscillating electric fields when electric fields with $E=0.25 \mathrm{~V} \mathrm{\AA}^{-1}$ and $100 \mathrm{GHz}$ were applied on ( $\left.\begin{array}{lll}0 & 0 & 1\end{array}\right)$ surface at $x, y$, and $z$ directions. It shows that the electric fields can induce the directional arrangement of water molecules following the oscillating electric fields. It is obvious that $\mu_{x}, \mu_{y}$ and $\mu_{z}$ have the same phenomenon of sinusoidal variation over time according with the frequency of electric field. But $\mu_{x}$ is almost equal to $\mu_{y}$, and $\mu_{z}$ is less than $\mu_{x}$. We can infer that the orientations of dipoles of more water molecules do not follow the directions of electric fields when the electric field was applied in the $z$ direction compared with $x$ or $y$ direction. To describe the orientations of water molecules, we define

$$
\cos \theta_{n}=\frac{\mu_{n}}{\mu} \quad(n=x, y, z)
$$

where $\theta$ is the angle between the dipole direction of water molecules and the direction of electric field. Fig. 5b shows the statistical results of $\cos \theta$ at the moment that dipole moment along the direction of electric field is maximum. It is clear that most of $\cos \theta_{x}$ and $\cos \theta_{y}$ of water molecules are distributed in the range of 0.75 to 1 when the electric fields were applied along $x$ and $y$ directions. It means that most water molecules are well aligned with the electric field. However, when the electric field was applied along $z$ direction, the $\cos \theta_{z}$ of water molecules are nearly distributed evenly between -1 and 1 , although the number of water molecules with positive $\cos \theta_{z}$ is slightly higher than that with negative value. That is why $\mu_{z}$ is less than $\mu_{x}$ or $\mu_{y}$, and the amounts of water molecules desorb by $z$ direction electric field is less than that of $x$ or $y$ direction electric field. Similar statistical results can also be obtained on the $\left(\begin{array}{lll}0 & 0-1\end{array}\right)$ surface, as shown in Fig. 5c and d. According to the response of water molecules to the oscillating electric fields with different directions, we can infer that the orientations of water molecules in the pores are determined by the orientations of electric field, hydroxyl groups, and the positions of water molecules.

In order to better verify the effects of the positions of water molecules on their orientations in electric fields, we calculated the average $\cos \theta$ of adsorption layer and bulk phase layer on the (llll $\left.\begin{array}{lll}0 & 0 & 1\end{array}\right)$ surface with different electric directions, respectively, as shown in Fig. 6. It is clear that most of the water molecules in both adsorption layer and bulk phase are aligned along the direction of the electric field no matter which direction of electric field was applied, but the direction of molecules in bulk phase is closer to the direction of electric field. It means that the (a)

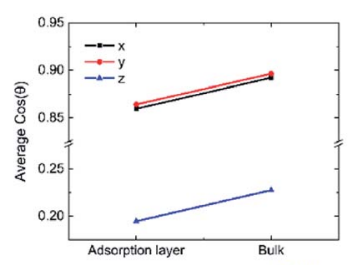

(c)

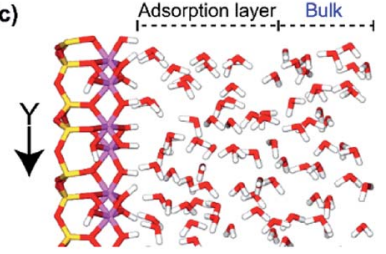

(b)

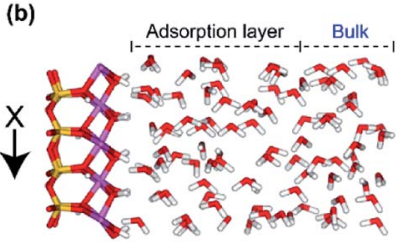

(d)

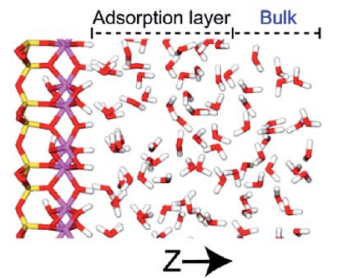

Fig. 6 Snapshot of simulation model of $\left(\begin{array}{llll}0 & 0 & 1\end{array}\right)$ surface after applying electric fields in different directions, (a) statistics on each layered of average $\cos (\theta)$, (b) $x$ direction, (c) $y$ direction and (d) $z$ direction.

dipole moment of water molecules in adsorption layer is less susceptible to the electric field than the adsorbed layer molecules because of the stronger action of hydrogen bonds between hydroxyl and water molecules. And much more water molecules are well aligned with $x$ and $y$ direction electric field, demonstrated in Fig. 6b-d. Because of the fixed hydroxyls on the surface, the water molecules in the adsorption layer are more
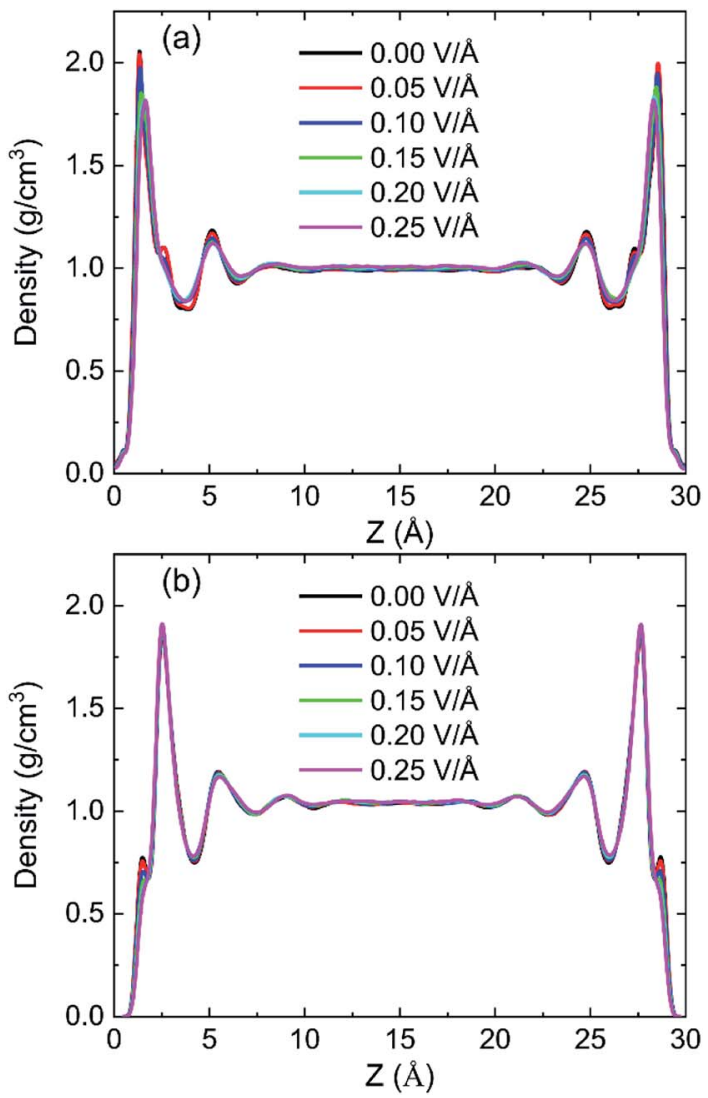

Fig. 7 Density distribution of water in the pore along the $z$ direction of simulation model with different intensity of oscillating electric fields (333.15 K, y direction): (a) (0 0 1) surface, (b) (0 0 -1) surface. 
difficult to rotate with the oscillating electric field than those in bulk phase.

As can be seen from the above discussion, the electric field parallel to the surface of the kaolinite (include $x$ and $y$ directions) has a significantly greater effect on the behaviour of water than the electric field normal to the surface of the kaolinite.

\subsection{Effects of the intensity of oscillating electric field on water behaviour}

In order to research the effects of the intensity of oscillating electric field on the behaviour of water in kaolinite pore, the density distribution of 898 water molecules with different intensity of electric fields were applied in $y$ direction are shown in Fig. 7. It is obvious that the density of adsorption layer of water molecules shows a downward tendency. The peak of the first adsorption layer decreases from $2.06 \mathrm{~g} \mathrm{~cm}^{-3}$ to $2.04 \mathrm{~g} \mathrm{~cm}^{-3}$, $1.98 \mathrm{~g} \mathrm{~cm}^{-3}, 1.85 \mathrm{~g} \mathrm{~cm}^{-3}, 1.82 \mathrm{~g} \mathrm{~cm}^{-3}$ and $1.81 \mathrm{~g} \mathrm{~cm}^{-3}$ when the electric fields with $0.00 \mathrm{~V} \AA^{-1}, 0.05 \mathrm{~V}^{-1}, 0.10 \mathrm{~V}^{-1}, 0.15 \mathrm{~V}^{-1}$, $0.20 \mathrm{~V}^{-1}$ and $0.25 \mathrm{~V}^{-1}$ were introduced into the pore formed by $\left(\begin{array}{lll}0 & 0 & 1\end{array}\right)$ surface, respectively. Meanwhile, the position of first adsorption peak moves away from the surface to the center from

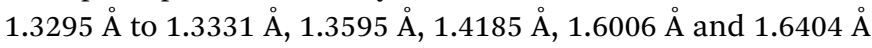
when electric fields with the above intensity were introduced. It indicates that some water molecules gradually broke away the shackles of the kaolinite and dissociate from the surface to center of pore with the increase of electric field intensity. But the effects of electric field intensity on density distribution of water in the pore formed by $\left(\begin{array}{ll}0 & 0-1\end{array}\right)$ surface are not evident, as Fig. $7 \mathrm{~b}$ shows. The value and the position of the adsorption layer are almost unchanged with the increase of electric field intensity, indicating that the reaction of water molecules adsorbed on $\left(\begin{array}{lll}0 & 0 & 1\end{array}\right)$ surface to the increase of electric field is more obvious than that of $\left(\begin{array}{lll}0 & 0 & -1\end{array}\right)$ surface. It can be explained from the effects of intensity of electric field on the number of hydrogen bonds formed between water molecules and the surface of kaolinite.

More hydrogen bonds are formed between water molecules and the hydroxyl groups on $\left(\begin{array}{lll}0 & 0 & 1\end{array}\right)$ surface than that formed

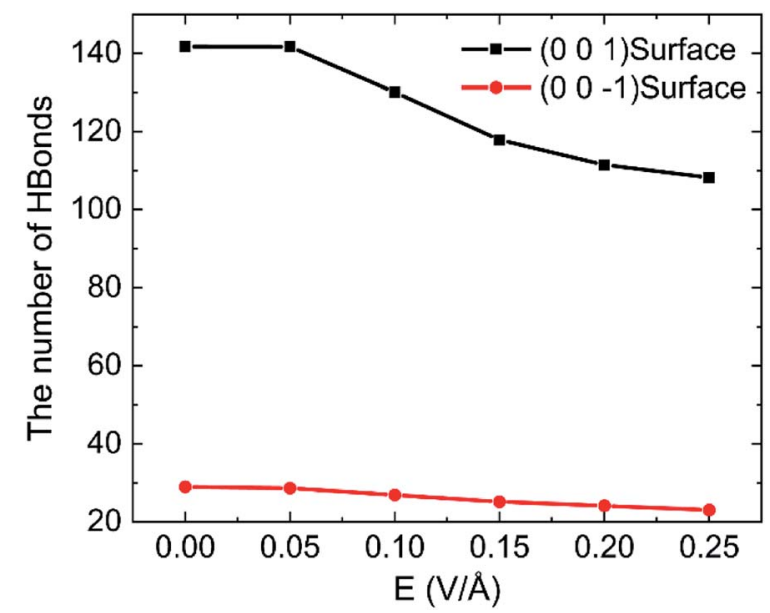

Fig. 8 The average number of hydrogen bonds with different oscillating electric fields. between water molecules and the oxygen atoms on $\left(\begin{array}{lll}0 & 0 & -1\end{array}\right)$ surface, as shown in Fig. 8. The number of hydrogen bonds slightly decreases when electric field of $0.05 \mathrm{~V}^{-1}$ was applied and remarkably decreases with a continuous increasing intensity of electric field. The average number of hydrogen bonds on (ll $\left.\begin{array}{lll}0 & 1\end{array}\right)$ surface decreases from 141.72 to 108.22 and the average number of hydrogen bonds on $\left(\begin{array}{lll}0 & 0 & -1\end{array}\right)$ surface decreases from 28.99 to 23.01 when electric fields of $0.25 \mathrm{~V}^{-1}$ was introduced to the system. Hydrogen bonds can be destroyed by oscillating electric fields because water molecules would rotate following the frequency of applied electric fields. ${ }^{33}$ It is concluded that hydrogen bonds are more prone to be destroyed to electric fields with stronger intensity. Although, the amounts of water molecules desorbed from $\left(\begin{array}{lll}0 & 0 & -1\end{array}\right)$ surface is not obvious with the increase of intensity.

The RDFs between oxygen of hydroxyl on $\left(\begin{array}{lll}0 & 0 & 1\end{array}\right)$ surface of kaolinite and oxygen of water $\left(\mathrm{O}_{\mathrm{Sur}(1)}-\mathrm{O}_{\mathrm{W}}\right)$ and the RDFs between oxygen of kaolinite on $\left(\begin{array}{lll}0 & 0 & -1\end{array}\right)$ surface and oxygen of water $\left(\mathrm{O}_{\mathrm{Sur}(-1)}-\mathrm{O}_{\mathrm{W}}\right)$ are shown in Fig. 9. It is distinct from the graph that the value of the first peak of RDFs decreases with the increase of intensity of oscillating electric fields, but the position of the peak keeps constant for both $\mathrm{O}_{\mathrm{Sur}(1)}-\mathrm{O}_{\mathrm{W}}$ and $\mathrm{O}_{\mathrm{Sur}(-1)}-\mathrm{O}_{\mathrm{W}}$. The results show that the distance between some
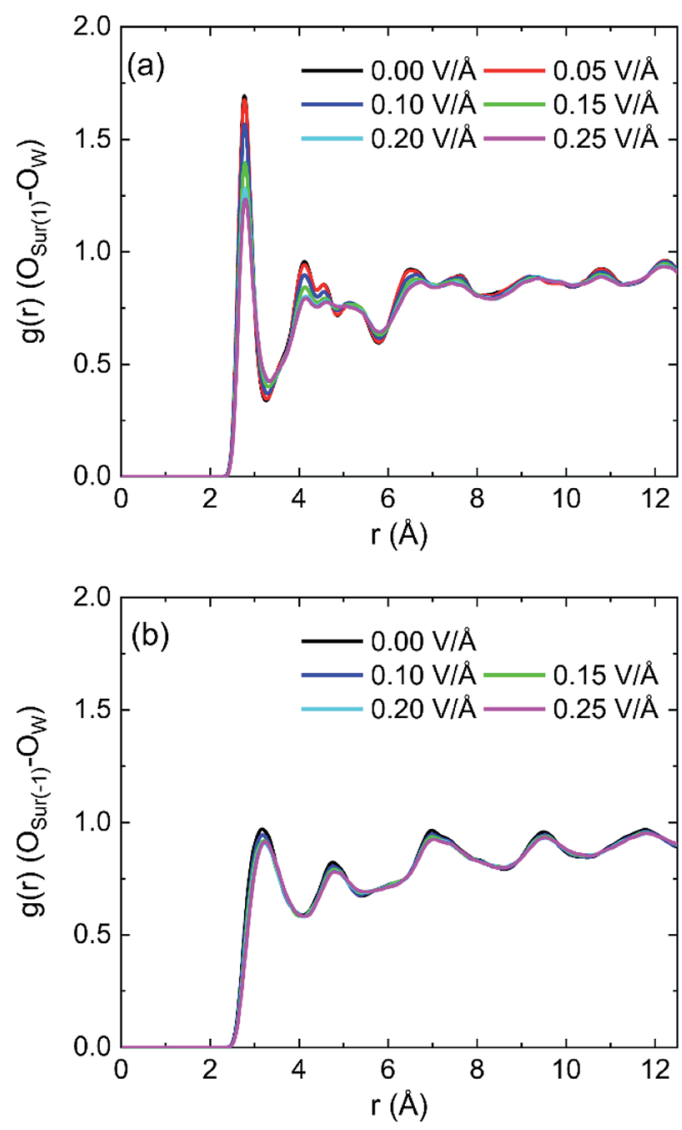

Fig. 9 The RDFs between water and atoms in kaolinite with different intensity of electric fields $(333.15 \mathrm{~K}, 100 \mathrm{GHz})$ : (a) oxygen of hydroxyl on the $\left(\begin{array}{lll}0 & 0 & 1\end{array}\right)$ surface of kaolinite and oxygen of water $\left(\mathrm{O}_{\mathrm{sur}(1)}-\mathrm{O}_{\mathrm{w}}\right)$, (b) oxygen of hydroxyl on the $(00-1)$ surface of kaolinite and oxygen of water $\left(\mathrm{O}_{\text {sur(-1) }}-\mathrm{O}_{\mathrm{W}}\right)$. 


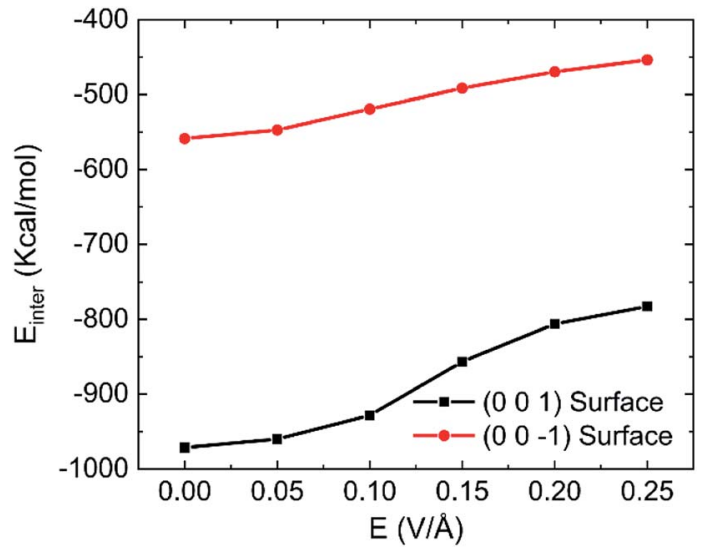

Fig. 10 Effects of different intensity on the interaction energy between water and kaolinite $(100 \mathrm{GHz}, 333.15 \mathrm{~K})$.

oxygen atoms of water and the oxygen atoms of hydroxyl gradually increase and the water molecules move away from the wall with the increase of intensity of oscillating electric fields. It also means electric fields with stronger intensity can lead to a bigger decrease of the number of hydrogen bonds. It is obvious that the first peak of $\mathrm{O}_{\mathrm{Sur}(1)}-\mathrm{O}_{\mathrm{W}}$ is closer slightly to the surface than the first peak of $\mathrm{O}_{\mathrm{Sur}(-1)}-\mathrm{O}_{\mathrm{W}}$. It is consistent with the conclusion above.
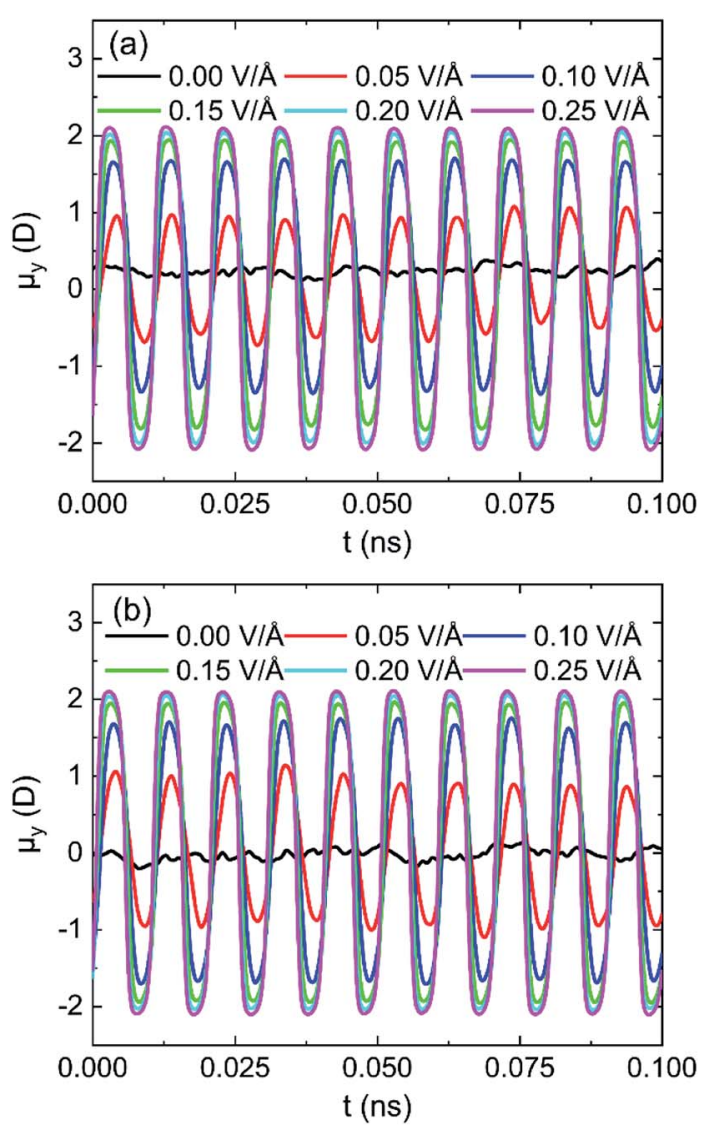

Fig. 11 System $y$ component of the average dipole moment for different intensity of electric fields $100 \mathrm{GHz}$ on (a) $(00$ 1) surface and (b) $(00-1)$ surface.
Fig. 10 shows the effects of intensity of oscillating electric fields on interaction energy between water and kaolinite. We can clearly see that the interaction energy between the $\left(\begin{array}{lll}0 & 0 & 1\end{array}\right)$ surface of kaolinite and water molecules is about twice of that of $\left(\begin{array}{lll}0 & 0 & -1\end{array}\right)$ surface because water molecules can form more hydrogen bonds with the $\left(\begin{array}{lll}0 & 0 & 1\end{array}\right)$ surface of kaolinite. The interaction energy between water molecules and kaolinite increases with the increase of intensity of electric fields. And the oscillating electric fields have a stronger influence on the interaction of $\left(\begin{array}{lll}0 & 0 & 1\end{array}\right)$ surface of kaolinite with water molecules than that of $\left(\begin{array}{lll}0 & 0 & -1\end{array}\right)$ surface. Actually, hydrogen bond plays an important role in the interaction energy between water molecules and kaolinite. The interaction between kaolinite and water molecules becomes weaker when stronger intensity electrical fields were introduced because more hydrogen bonds were destroyed by oscillating electric field.

The effects of intensity of oscillating electric fields on average dipole moment $(\mu)$ of 898 water molecules on $\left(\begin{array}{lll}0 & 0 & 1\end{array}\right)$ and $\left(\begin{array}{lll}0 & 0 & -1\end{array}\right)$ surface are shown in Fig. 11a and b, respectively. It is clear that water molecules rotate following the frequency of applied electric fields and lead to dipolar alignment with the fields, no matter water molecules are in the pore formed by $(0$ $\left.\begin{array}{ll}0 & 1\end{array}\right)$ or $\left(\begin{array}{ll}0 & 0\end{array}-1\right)$ surface. The peak of the average dipole moment of water molecules in $y$ component increases with the increase of intensity of electric field. It can infer that stronger applied
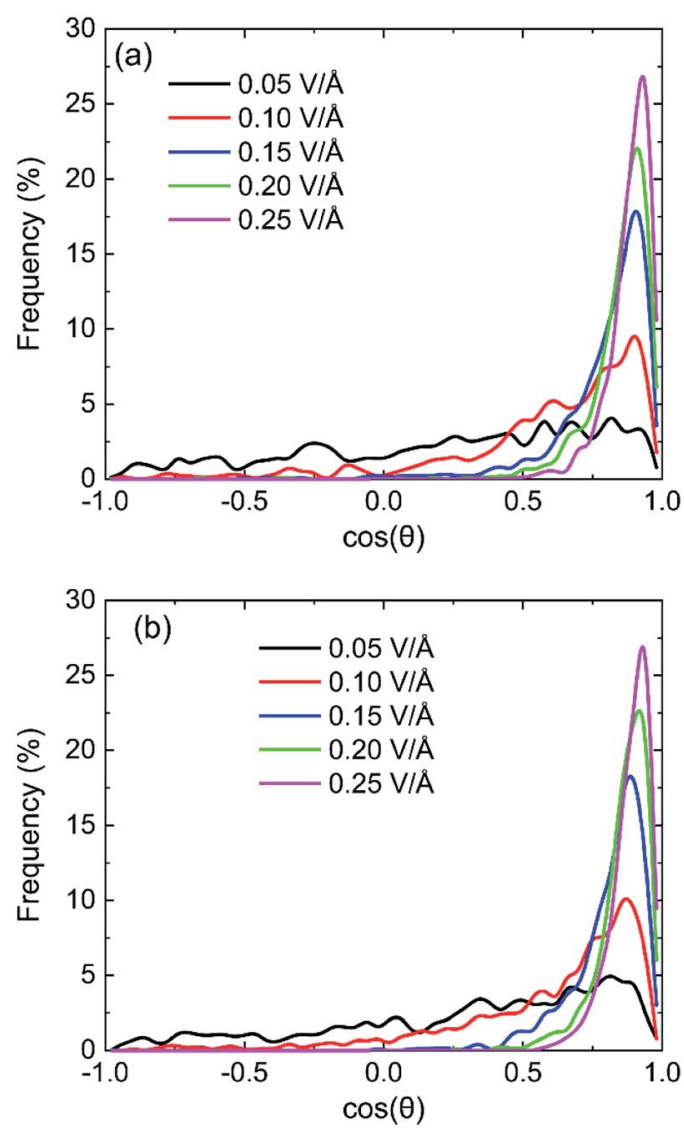

Fig. 12 The statistical results of $\cos \theta$ at the moment of maximum of dipole moment with the field of $100 \mathrm{GHz}$ on (a) $(00$ 1) surface and (b) (0 0 -1) surface. 


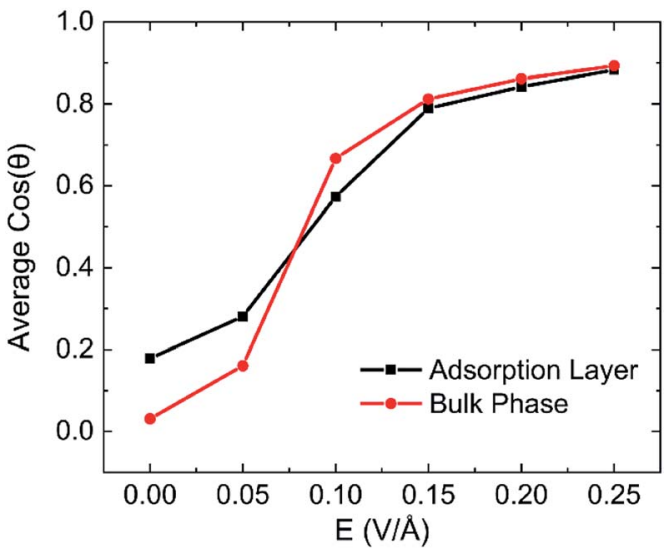

Fig. 13 The statistics on each layered of average $\cos (\theta)$ after applying electric fields on $\left(\begin{array}{llll}0 & 0 & 1\end{array}\right)$ surface in $y$ direction with different intensity.

electric fields can better overcome the interaction between water molecules and lead to a better alignment.

The statistical results of $\cos \theta$ at the moment of maximum of dipole moment with the field of $100 \mathrm{GHz}$ on $\left(\begin{array}{lll}0 & 0 & 1\end{array}\right)$ and $\left(\begin{array}{lll}0 & 0 & -1\end{array}\right)$ surface are shown in Fig. 12. The larger the value of $\cos \theta$ is, the smaller the angle between the direction of the dipole moment of
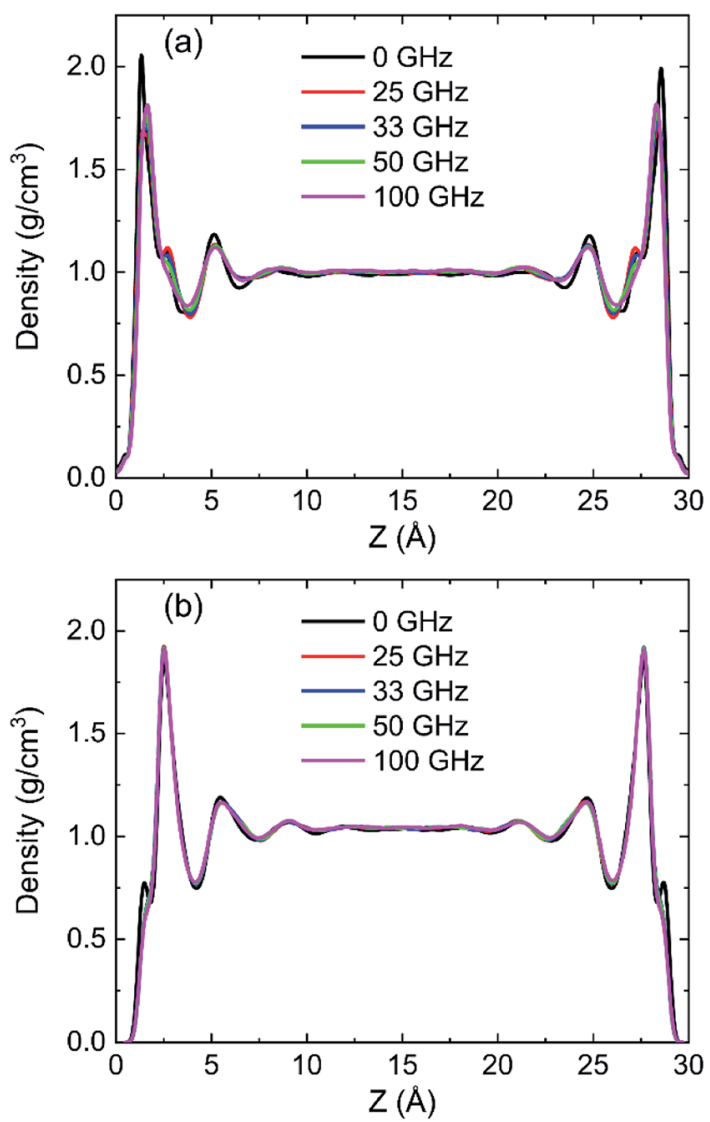

Fig. 14 Density distribution of water in the pore along the $z$ direction of simulation model with different frequency of oscillating electric fields on (a) $\left(\begin{array}{lll}0 & 0 & 1\end{array}\right)$ surface and (b) $(0 \quad 0-1)$ surface $(333.15 \mathrm{~K}, y$ direction). the water molecule and the direction of the electric field is. It is clear that the percentage of dipole alignment to the direction of field gradually increases with the increase of intensity of oscillating electric fields both on $\left(\begin{array}{lll}0 & 0 & 1\end{array}\right)$ surface and $\left(\begin{array}{lll}0 & 0 & -1\end{array}\right)$ surface. The electrical force exerted on a water molecule by stronger electric field can further overcome the actions of other molecules on it and more water molecules can rotate following the oscillating electric fields according to the direction of applied oscillating electric fields. Comparing the percentage data, we can find that the percentage of dipole alignment of $\left(\begin{array}{lll}0 & 0 & -1\end{array}\right)$ surface with higher $\cos \theta$ is slightly bigger than that of $\left(\begin{array}{lll}0 & 0 & 1\end{array}\right)$ surface. It can infer that the water molecules on the silicon oxide surface are more likely to align along the direction of the electric field than the water molecules on the hydroxyl surface.

The effects of intensity of electric field on alignment of water molecules depend on the position of the molecule, as shown in Fig. 13. It is obvious that both the average $\cos \theta$ of adsorption layer and bulk phase increase with the increase of intensity of electric field. It means that the number of water molecule aligned with electric field increases with the increase in intensity of electric field. The direction of molecules of water in bulk phase is almost random when no electric field is absent. But direction of molecules of water in adsorbed layer aligns in the $y$ direction to some extent because of the interaction between
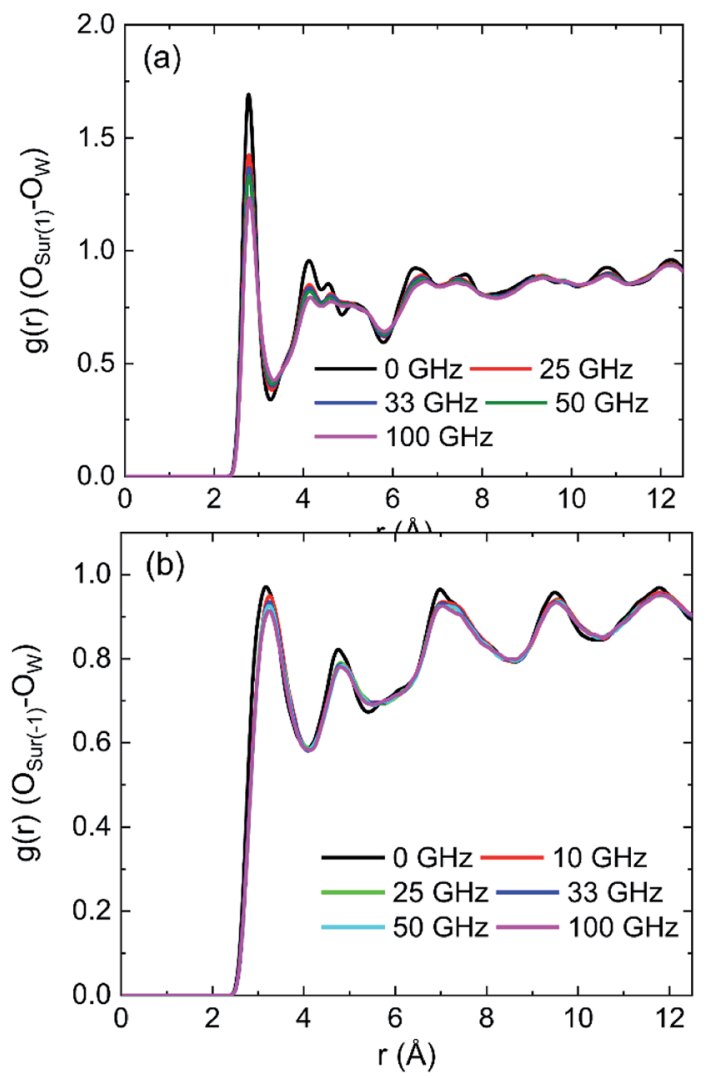

Fig. 15 The RDFs between water and atoms in kaolinite with different frequency of electric fields: (a) oxygen of hydroxyl on the $\left(\begin{array}{lll}0 & 0 & 1\end{array}\right)$ surface of kaolinite and oxygen of water $\left(\mathrm{O}_{\text {sur(1) }}-\mathrm{O}_{\mathrm{w}}\right)$, (b) oxygen of silica on the $(00-1)$ surface of kaolinite and oxygen of water $\left(\mathrm{O}_{\mathrm{sur}(-1)}-\right.$ $\mathrm{O}_{\mathrm{w}}$. 
kaolinite and water molecules. The molecules of water in bulk phase are easier than that in adsorption layer to rotate following the direction of applied electric fields and lead to dipolar alignment with the fields. The average $\cos \theta$ of molecules of water in bulk phase increases rapidly than that of adsorption layer. The average $\cos \theta$ of molecules of water in bulk phase is larger than that of adsorption layer when $E>0.1 \mathrm{~V}^{-1}$.

\subsection{Effects of the frequency of oscillating electric field on water behaviour}

Density distribution of water molecules were calculated to investigate the effects of frequencies of oscillating electric fields on adsorption of water molecules on ( $\left.\begin{array}{lll}0 & 0 & 1\end{array}\right)$ and $\left(\begin{array}{lll}0 & 0 & -1\end{array}\right)$ surface of kaolinite are shown in Fig. 14. The position of the peak of the first adsorption layer moves form $1.3295 \AA$ to $1.4015 \AA$ A $1.6276 \AA$, $1.6331 \AA$ and $1.6438 \AA$ when electric fields with frequencies of 25 $\mathrm{GHz}, 33 \mathrm{GHz}, 50 \mathrm{GHz}, 100 \mathrm{GHz}$ were applied in the pore formed by $\left(\begin{array}{lll}0 & 0 & 1\end{array}\right)$ surface, as Fig. 14a shows. And there is a slight decrease of the peak of the first adsorption layer when higher frequency electric fields were introduced. It means that the water molecules show a tendency to keep away from the surface when higher frequency electric fields were introduced. But the effects of frequency of electric fields to the density distribution of water molecules on $\left(\begin{array}{lll}0 & 0 & -1\end{array}\right)$ surface of kaolinite are
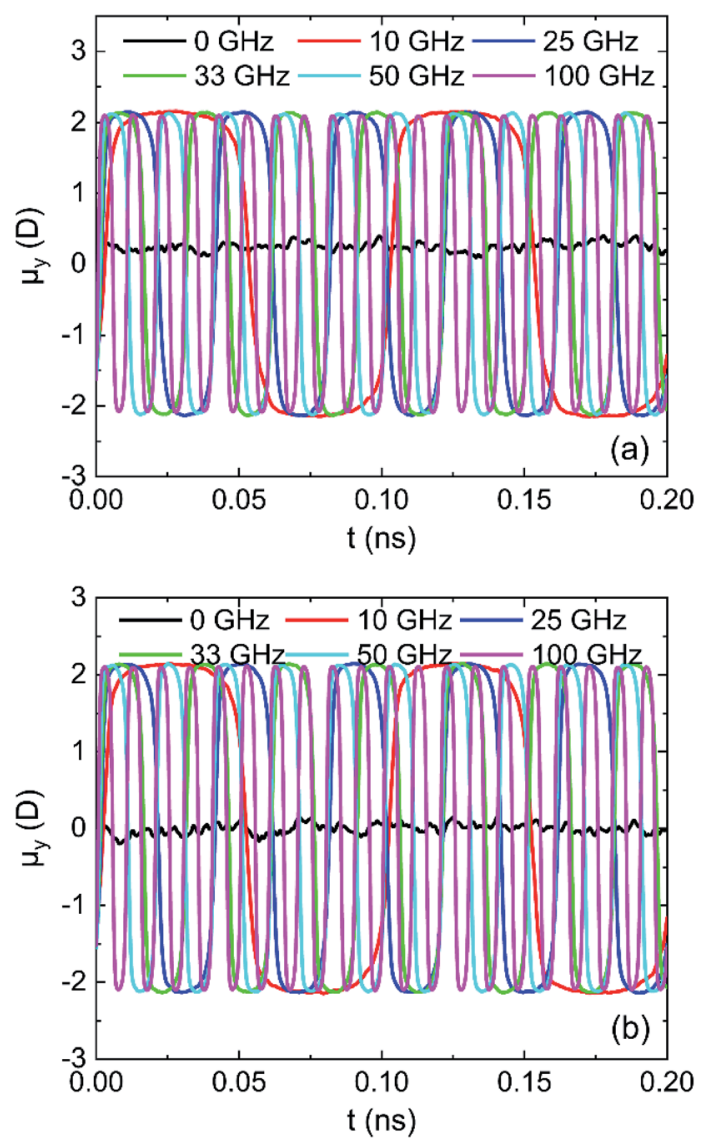

Fig. 16 System $y$ component of the total dipole moment in $0.25 \vee \AA^{-1}$ fields: (a) $(00$ 1) surface and (b) $(00-1)$ surface.
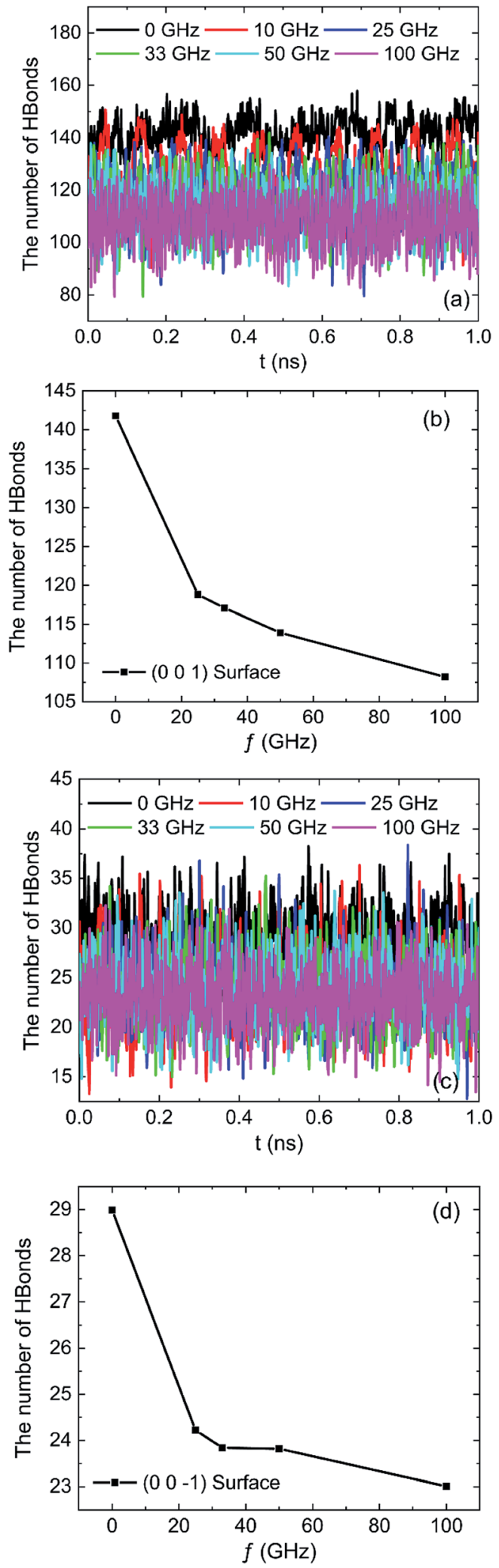

Fig. 17 The number of hydrogen bonds under different oscillating

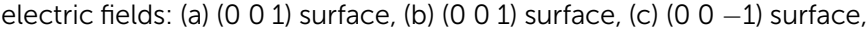
(d) $(00-1)$ surface. 
inconspicuous. The peak of the adsorption layers did not change significantly with the increase of frequency, as Fig. 14b shows.

The RDFs between oxygen of hydroxyl on the $\left(\begin{array}{lll}0 & 0 & 1\end{array}\right)$ surface of kaolinite and oxygen of water $\left(\mathrm{O}_{\mathrm{Sur}(1)}-\mathrm{O}_{\mathrm{W}}\right)$ and the RDFs between oxygen of silica on the $\left(\begin{array}{ll}0 & 0-1\end{array}\right)$ surface of kaolinite and oxygen of water $\left(\mathrm{O}_{\mathrm{Sur}(-1)}-\mathrm{O}_{\mathrm{W}}\right)$ are shown in Fig. 15. It is distinct from the graph that the value of the first peak of RDFs decreases with the increase of frequency of oscillating electric fields and the position of the peak keep constant for both $\mathrm{O}_{\mathrm{Sur}(1)}-\mathrm{O}_{\mathrm{W}}$ and $\mathrm{O}_{\text {Sur(-1) }}-\mathrm{O}_{\mathrm{W}}$. It is also obvious that the first peak of $\mathrm{O}_{\mathrm{Sur}(1)}-\mathrm{O}_{\mathrm{W}}$ is closer to the surface than the first peak of $\mathrm{O}_{\mathrm{Sur}(-1)}-\mathrm{O}_{\mathrm{W}}$, corresponding to the density distribution of water molecules.

The results in Fig. 16 for $\mu_{y}$ of water in oscillating electric fields with $0.25 \mathrm{~V}^{-1}$ on $\left(\begin{array}{lll}0 & 0 & 1\end{array}\right)$ and $\left(\begin{array}{lll}0 & 0 & -1\end{array}\right)$ surface show that water molecules rotate following the oscillating electric fields according to the frequency of applied electric fields, leading to dipolar alignment with the fields. ${ }^{33}$ The water molecules rotate faster as the frequency of electric field increases, which can destroy more hydrogen bonds.

The effects of frequencies of oscillating electric fields on the number of hydrogen bonds which are formed between water molecules and the hydroxyl groups on $\left(\begin{array}{lll}0 & 0 & 1\end{array}\right)$ surface or oxygen atoms on $\left(\begin{array}{lll}0 & 0 & -1\end{array}\right)$ surface are shown in Fig. 17. The results clearly show that the frequency of oscillating electric fields have biggish effect on the number of hydrogen bonds due to the fact that water molecule is polar molecules. There is a sharp decrease of hydrogen bonds because of the rotation of water molecule when $10 \mathrm{GHz}$ electric field is applied. The trend of number of hydrogen bond decline is slowing down with the increase of frequency of electric field, as Fig. 17b and d show.

The effects of frequency of oscillating electric fields on interaction energy between water and kaolinite are as shown in Fig. 18. It is clear that the interaction between water and $\left(\begin{array}{lll}0 & 0 & 1\end{array}\right)$ surface of kaolinite is much stronger than $\left(\begin{array}{lll}0 & 0 & -1\end{array}\right)$ surface of kaolinite because more hydrogen bonds are formed on it. The interaction energy of water molecules and $\left(\begin{array}{lll}0 & 0 & 1\end{array}\right)$ surface and $\left(\begin{array}{ll}0 \\ 0\end{array}\right.$ $0-1)$ surface of kaolinite gradually increase with the increase of

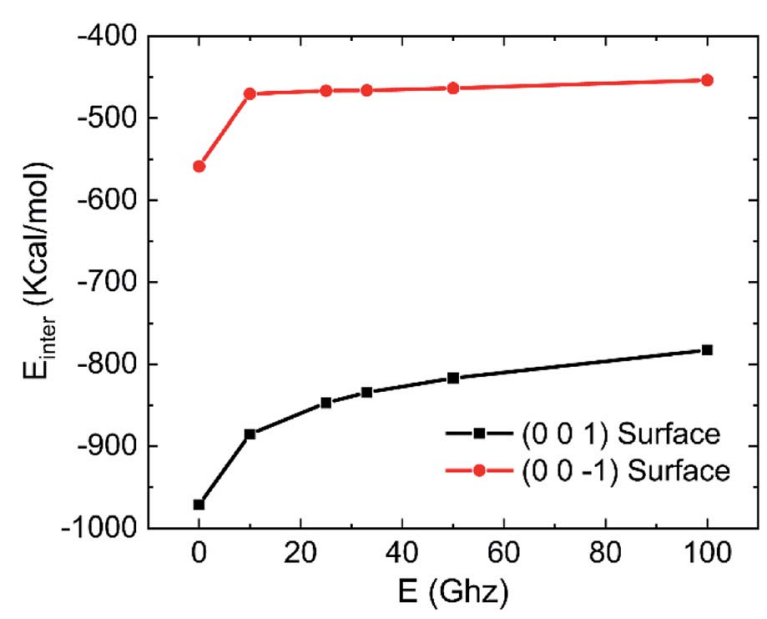

Fig. 18 Effects of frequency on the interaction energy between water and kaolinite $\left(0.25 \vee \AA^{-1}, 333.15 \mathrm{~K}\right)$. frequency of electric fields. The increase of interaction energy between water and ( $\left.\begin{array}{lll}0 & 0 & 1\end{array}\right)$ surface is more obvious than that between water and $\left(\begin{array}{lll}0 & 0 & -1\end{array}\right)$ surface. It means that the effect of electric fields on the interaction between water molecules and $(0$ $0-1)$ surface of kaolinite is limited. It is consistent with the conclusion above.

\section{Conclusions}

Molecular dynamic simulations were employed to research the effects of oscillating electric fields on adsorption/desorption behaviour of water molecules on kaolinite $\left(\begin{array}{lll}0 & 0 & 1\end{array}\right)$ and $\left(\begin{array}{lll}0 & 0 & -1\end{array}\right)$ surface. Introducing electric fields with different directions, intensities, and frequencies, the density distribution of water was analyzed. The mechanisms of water adsorption on different kaolinite surfaces in oscillating electric fields were explored by dipole moment, radial distribution functions, hydrogen bonds, and interaction energy. The main conclusions are as follows:

(1) Theoretically, introducing oscillating electric fields could affect the adsorption/desorption behaviour of water in the pore of kaolinite because of the polarity of water molecules.

(2) The $\left(\begin{array}{lll}0 & 0 & 1\end{array}\right)$ surface of kaolinite was more hydrophilic than $\left(\begin{array}{lll}0 & 0 & -1\end{array}\right)$ surface because hydrogen bonds were easily formed between hydroxyl and water molecules. More water molecules desorbed from the $\left(\begin{array}{lll}0 & 0 & 1\end{array}\right)$ surface of kaolinite when electric fields were applied in the direction that parallel to kaolinite surface. The effects of oscillating electric fields were not obvious on adsorption/desorption behaviour of water molecules on the $\left(\begin{array}{lll}0 & 0 & -1\end{array}\right)$ surface of kaolinite.

(3) Introducing oscillating electric fields could lead to decrease adsorption of water and the thicker adsorption layer. The adsorption of water decreased with the increase of frequency or intensity of the electric fields.

(4) The applied oscillating fields reduces the number of hydrogen bonds formed on the interfaces of water-kaolinite due to water molecules re-orientates following the oscillating electric fields. More hydrogen bonds were broken by electric fields of stronger intensity or higher frequency.

(5) The interaction energy of $\mathrm{H}_{2} \mathrm{O}$-kaolinite increased with the intensity and frequency of the applied oscillating electric fields.

\section{Conflicts of interest}

There are no conflicts to declare.

\section{Acknowledgements}

This research was financially supported by the National Natural Science Foundation of China (51574268), the Shandong Province Natural Science Foundation (ZR2014EEM050) and the Graduate Innovation Fund of China University of Petroleum (YCX2019089). 


\section{References}

1 B. Zhang, J. Kang and T. Kang, Appl. Surf. Sci., 2018, 439, 792800.

2 B. Rotenberg, V. Marry, N. Malikova and P. Turq, J. Phys.: Condens. Matter, 2010, 22, 284114.

3 D. M. Jarvie, AAPG Mem., 2012, 97, 89-119.

4 D. Tunega, M. H. Gerzabek and H. Lischka, J. Phys. Chem. B, 2004, 108, 5930-5936.

5 B. K. Benazzouz, A. Zaoui and A. B. Belonoshko, Am. Mineral., 2013, 98, 1881-1885.

6 Q. Chi, R. Zhen, X. Wang, K. Yang, Y. Jiang, F. Li and B. Xue, Polym. Bull., 2017, 74, 3089-3108.

7 A. Fujishima and K. Honda, Nature, 1972, 238, 37-38.

8 Z. Futera and N. J. English, J. Chem. Phys., 2016, 145, 204706.

9 J. L. Munholland, K. G. Mumford and B. H. Kueper, J. Contam. Hydrol., 2016, 184, 14-24.

10 B. O'Regan and M. Grätzel, Nature, 1991, 353, 737-740.

11 M. Atilhan and S. Aparicio, J. Phys. Chem. B, 2017, 121, 221232.

12 H. Ren, L. Zhang, X. Li, Y. Li, W. Wu and H. Li, Phys. Chem. Chem. Phys., 2015, 17, 23460-23467.

13 X. Li, H. Li and G. Yang, J. Colloid Interface Sci., 2017, 501, 54-59.

14 Y. Wang, B. Liao, L. Qiu, D. Wang and Q. Xue, Int. J. Heat Mass Transfer, 2019, 128, 1218-1228.

15 Z. Futera and N. J. English, J. Phys. Chem. C, 2016, 120, 19603-19612.

16 Z. Futera and N. J. English, J. Chem. Phys., 2017, 147, 031102.

17 F. Song, L. Ma, J. Fan, Q. Chen, G. Lei and B. Q. Li, Phys. Chem. Chem. Phys., 2018, 20, 11987-11993.

18 F. Song, L. Ma, J. Fan, Q. Chen, L. Zhang and B. Q. Li, Nanomaterials, 2018, 8, 340.

19 D. Y. Zong, Z. Yang and Y. Y. Duan, Appl. Therm. Eng., 2017, 122, 71-79.

20 X. Gao, T. Zhao and Z. Li, Phys. Rev. E: Stat., Nonlinear, Soft Matter Phys., 2015, 92, 023017.

21 H. Zhang, B. Liu, M. S. Wu, K. Zhou and A. W. K. Law, Comput. Mater. Sci., 2017, 131, 100-107.
22 D. Zong, H. Hu, Y. Duan and Y. Sun, J. Phys. Chem. B, 2016, 120, 4818-4827.

23 R. Srivastava, J. K. Singh and P. T. Cummings, J. Phys. Chem. C, 2012, 116, 17594-17603.

24 B. Rotenberg, V. Marry, R. Vuilleumier, N. Malikova, C. Simon and P. Turq, Geochim. Cosmochim. Acta, 2007, 71, 5089-5101.

25 G. Odriozola and F. D. Guevara-Rodriguez, Langmuir, 2004, 20, 2010-2016.

26 M. Chávez-Páez, K. Van Workum, L. de Pablo and J. J. de Pablo, J. Chem. Phys., 2001, 114, 1405-1413.

27 D. Liu, P. Yuan, H. Liu, T. Li, D. Tan, W. Yuan and H. He, Appl. Clay Sci., 2013, 85, 25-30.

28 A. Kadoura, A. K. Narayanan Nair and S. Sun, Microporous Mesoporous Mater., 2016, 225, 331-341.

29 A. Merkel, R. Fink and R. Littke, Int. J. Coal Geol., 2015, 147148, 1-8.

30 Q. Li, X. Li, S. Yang, P. Gu and G. Yang, ACS Omega, 2019, 4, 5932-5936.

31 N. K. Karna, A. Rojano Crisson, E. Wagemann, J. H. Walther and H. A. Zambrano, Phys. Chem. Chem. Phys., 2018, 20, 18262-18270.

32 D. L. Bish, Clays Clay Miner., 1989, 37, 289-296.

33 G. Ciccotti, M. Ferrario and C. Schuette, Entropy, 2014, 16, 233.

34 R. T. Cygan, J. J. Liang and A. G. Kalinichev, J. Phys. Chem. B, 2004, 108, 1255-1266.

35 Y. D. Wang, B. Liao, Z. Y. Kong, Z. G. Sun, L. Qiu and D. S. Wang, Energy Fuels, 2018, 32, 11440-11451.

36 Y. Wang, B. Liao, Z. Kong, Z. Sun, L. Qiu and D. Wang, Energy Fuels, 2018, 32, 11440-11451.

37 S. Plimpton, J. Comput. Phys., 1995, 117, 1-19.

38 D. J. Evans and B. L. Holian, J. Chem. Phys., 1985, 83, 40694074.

39 Y. Okuno, M. Minagawa, H. Matsumoto and A. Tanioka, J. Mol. Struct.: THEOCHEM, 2009, 904, 83-90.

40 D. Argyris, D. R. Cole and A. Striolo, J. Phys. Chem. C, 2009, 113, 19591-19600.

41 H. J. Dong, J. H. Yang and S. J. Mu, Chem. Phys., 1999, 244, 331-337. 